\title{
Factors associated with motivation of health workers in Moshi rural district 2005
}

\author{
Eliakimu Godfrey, MD5 (2006/2007)
}

\begin{abstract}
Objectives; To assess the staffing gap by cadre in the health facilities, determining the proportion of health workers motivated and assessing the factors associated with their motivation

Study design; Descriptive cross sectional study

Settings; Moshi Rural district

Results; It was found that the staffing gap were $42.3 \%, 38.2 \%$ and $46.2 \%$ in the hospitals, health centres and dispensaries respectively. Comparison was made between the public, private and religious health facilities. It was found that $21.2 \%, 62.5 \%$ and $95.8 \%$ of health workers from public, private and religious health facilities respectively reported of presence of enough working equipment in their health facilities. In addition $36.1 \%, 54.3 \%$ and $81.6 \%$ of health workers from public, private and religious health facilities were being promoted when deserving. From the information above it is evident that health workers from religious health facilities have the highest level of motivation, those from the private health facilities are moderately motivated while those from public health facilities are poorly motivated.
\end{abstract}

\section{Conclusion and Recommendations}

Motivation of health workers and availability of working equipments in Moshi rural is highest in religious health facilities, moderate in private health facilities and lowest in public health facilities .

Efforts should be made to find affordable means of motivating the rural health workers so as to improve their performance and ultimately the health status of Tanzanians.

\section{INTRODUCTION}

In Southern Africa, we have a problem of inadequate health personnel compared to population. More than three quarters of countries in sub-Saharan Africa fall short of the WHO's minimum standard of 20 doctors per 100,000 and 13 countries have five or fewer per 100,000 people (1).In Southern Africa there is also a misdistribution of health personnel between: public and private health facilities; urban and rural areas; wealthy urban and underserved per urban areas; tertiary and primary (1).

A major cause of the misdistribution of health workers is the movement of health workers from areas of low socio-economic development to more highly developed areas (2). Health workers are migrating from rural health facilities to urban health facilities, others from public health facilities to private health facilities while others are migrating to neighbouring countries. Others run away completely from the profession to become merchants and politicians. "Policy makers in all countries are concerned about 'brain drain' of the health workforce within and between countries, although relevant research is still in its infancy (3)". There is an internal as well as international migration of health workers (3)". "Within a region is also movement from poorer to richer countries, for example from Zambia to South Africa, or from Tanzania to Botswana. (3)".

The rural health facilities have been facing severe shortage of health workers due to migration to urban health facilities. This has weakened the health system in rural areas (3). The few health workers who are still working there are working with low morale and the overall performance of their health facilities is poor (1)

\section{METHODOLOGY}

The study was conducted in Moshi rural district in Kilimanjaro. It was a descriptive cross-sectional study, the study of all health care providers. Four dispensaries, two health centers and two hospitals in Moshi rural from private, religious and public health facilities were incorporated in this study. 


\section{RESULTS}

A total number of health workers who responded to the questionnaires were 168; of which $76.8 \%$ were female and $23.2 \%$ were males. Analysis of socio-demographic characteristics indicated that out of 168 workers; $22 \%$ were clinicians; $66.1 \%$ were nurses and $11.9 \%$ were other cadres. Further analysis revealed that 97 health workers were from public; 16 from private health facilities and 55 from religious health facilities.

Analysis was done to assess the staffing gap by cadre at different levels of health facilities. The staffing gap for the medical officers and assistant medical officers were more than $60 \%$. The overall staffing gap was highest at the dispensary level $(46.2 \%)$ followed by hospital level (45.2\%) and finally the health center level $(38.2 \%)$.

Another analysis was done to asses the availability of various services to health workers in public, private and religious health facilities. More health workers from private and religious health facilities reported to have enough working equipment than those in public health facilities. The religious health facilities were leading in having health workers who are satisfied with their working environment. Fewer health workers from private health facilities were satisfied with the working environment than those from religious based health facilities. The religious health facilities were leading in promoting their health workers while the public health facilities were very poor in promoting their health workers.

TABLE: RESPONSES GIVEN BY HEALTH CARE PROVIDERS FROM PUBLIC, PRIVATE AND RELIGIOUS HEALTH FACILITIES ON AVAILABILITY OF VARIOUS SERVICES

\begin{tabular}{|c|c|c|c|}
\hline Question & $\begin{array}{l}\text { Proportion Of } \\
\text { Respondents Who Said } \\
\text { "Yes" From Public } \\
\text { Health Facilities }\end{array}$ & $\begin{array}{l}\text { Proportion Of } \\
\text { Respondents Who Said } \\
\text { "Yes" From Private } \\
\text { Health Facilities }\end{array}$ & $\begin{array}{l}\text { Proportion Of } \\
\text { Respondents Who Said } \\
\text { "Yes" From Religious } \\
\text { Health Facilities }\end{array}$ \\
\hline $\begin{array}{l}\text { 1. Do you have } \\
\text { enough working } \\
\text { equipment? }\end{array}$ & $21.2 \%$ & $62.5 \%$ & $95.8 \%$ \\
\hline $\begin{array}{l}\text { 2. Are you satisfied } \\
\text { with the working } \\
\text { environment }\end{array}$ & $23.6 \%$ & $52.6 \%$ & $80.3 \%$ \\
\hline $\begin{array}{l}\text { 3. Do you get your } \\
\text { salary on the } \\
\text { required time? }\end{array}$ & $82.2 \%$ & $88.2 \%$ & $91.5 \%$ \\
\hline $\begin{array}{l}\text { 4. Have you ever got } \\
\text { promotion when } \\
\text { deserving? }\end{array}$ & $36.1 \%$ & $54.3 \%$ & $81.6 \%$ \\
\hline
\end{tabular}

\section{DISCUSSION}

The staffing gap was analyzed cadre wise and at different facility levels. In comparison, the overall staffing gap was highest at the dispensary level (46.2\%). The overall staffing gap at the hospital level was slightly lower than that of the dispensary level as it was $(45.2 \%)$. The health center level had the lowest staffing gap (38.2\%) among the three levels of facility researched.

Analysis was made to establish the main reasons accounting for the observed staffing gap by interviewing the heads of the health facilities researched. The proportion of heads of facilities who gave the reasons were as follows. First inadequate incentives to health workers (85.7\%), secondly Qualified health personnel are not interested to work in rural areas due to poor infrastructure and poor means of earning money after office hours $(85.7 \%)$ and lastly, inadequate number of health workers employed by the government (57.1\%).

Availability of various services to health workers was assessed to determine the level of motivation of health workers working in the rural health facilities. Comparison was also made between public, private and religious based health facilities. Results revealed that there is more availability of various services to health workers working in private and religious health facilities than those working in public health facilities. 
The religious based health facilities were leading in having more health workers who are satisfied with their working environment. Fewer health workers from private health facilities were satisfied with their working environment. The public health facilities were leading in having many health workers who were not satisfied with their working environment. According to this study, the religious health facilities were leading in promoting their health workers, while the public health facilities were very poor in promoting their health workers.

Conclusion; The religious health facilities in Moshi rural are leading in promoting their health workers and availabilities of various services while the public health facilities are very poor in promoting their workers.

Recommendation; Efforts should be made to find affordable means of motivating the rural health workers so as to improve their performance and ultimately the health status of Tanzanians.

\section{REFERENCES}

1. Joint learning initiative. Human resources for health- overcoming the crisis. Cambridge, MA, Harvard
University Press, 2004 (http://www global health trust.org. report.html, 2005)

2. Travis $\mathrm{P}$ et al. overcoming the health systems constraints to achieve the millennium development goals. Lancert, 2004

3. World Health Organization (WHO) report, Health systems; improving performance. Geneva, WHO, 2000.

4. Tanzania Joint Health Review, Main Report, 28-30 April 2003.

5. Addressing Africa's health workforce crisis: an avenue for action paper prepared for high-level Forum on the health mdgs Abuja 2-3 December 2004

6. Commander, S; Kangasniemi, $M$; Winters, AL.The brain drain : curse or boon ?Survey of literature, 2001.

7. Iredale $R$. The migration of professionals; theories and typologies. International migration Quarterly review, 2001

8. Organization for economic, cooperation and development. Trends in international migration, annual report, Paris, 2001. 